\title{
Improving the Selectivity of the Phosphoric Acid $\beta$-Elimination on a Biotinylated Phosphopeptide
}

\author{
Lucrèce Matheron, ${ }^{1,2}$ Séverine Clavier, ${ }^{1,2}$ Oumar Diebate, ${ }^{1,2}$ Philippe Karoyan, ${ }^{1}$ \\ Gérard Bolbach, ${ }^{1}$ Dominique Guianvarc'h, ${ }^{1}$ Emmanuelle Sachon ${ }^{1,2}$
}

${ }^{1}$ Laboratoire des Biomolécules, Université P. et M. Curie, UMR 7203 UPMC-CNRS-ENS, 4, Place Jussieu, 75005 Paris, France

${ }^{2}$ Plateforme de Spectrométrie de Masse et Protéomique, Université P. et M. Curie, IFR83, 7-9 Quai Saint Bernard, 75005 Paris, France

\begin{abstract}
This study aims at improving the MALDI-TOF detection of a phosphorylated peptide containing a cysteine residue by $\beta$-elimination of $\mathrm{H}_{3} \mathrm{PO}_{4}$ hardly enriched by classical methods. The experimental conditions were optimized on this phosphopeptide (biot-pAdd) and its nonphosphorylated counterpart (biot-Add). The major side-reactions were $\mathrm{H}_{2} \mathrm{~S}$ elimination on the cysteine residues and $\mathrm{H}_{2} \mathrm{O}$ elimination on the non phosphorylated serine residue of biot-Add. The former dilutes the MALDI-TOF signal for the desired species. The latter gives a product similar to what is obtained by $\mathrm{H}_{3} \mathrm{PO}_{4}$ elimination and should prompt to caution when working with a mixture between phosphorylated and non phosphorylated peptides. Modifications on the solvent, the reaction temperature and time, the nature, and concentration of the base were made. Major improvement of the selectivity of the reaction was observed in $30 \% \mathrm{ACN}$, at room temperature for $4 \mathrm{~h}$. However, these optimizations are specific to these sequences and should be performed anew for different peptides. The selectivity of the reaction towards $\mathrm{H}_{3} \mathrm{PO}_{4}$ elimination is improved, but the persistence of side-reactions renders a previous sample fractionation necessary. In these optimized conditions, the ionization enhancement is 3-fold and the detection limits for biot-pAdd are similar to biot-Add (100 fmol).
\end{abstract}

Key words: Phosphopeptide, Phosphorylation, $\beta$-elimination, MALDI-TOF, Selectivity, Ionization efficiency

\section{Introduction}

Drotein phosphorylation is among the most abundant post-translational modification (PTM) to date [1-3] and plays a major role in biological functions [4-8]. Up to a third of human proteins could be phosphorylated at one or several

Electronic supplementary material The online version of this article (doi:10.1007/s13361-012-0467-y) contains supplementary material, which is available to authorized users.

Correspondence to: Emmanuelle Sachon; e-mail: emmanuelle.sachon (a) upmc.fr points [9], mostly on serine ( $\approx 90 \%)$, threonine $(\approx 10 \%)$, and tyrosine residues $(\approx 1 \%$ ) [10]. Mass spectrometry (MS) is now considered as a powerful analytical tool to study phosphoproteomes because of its high resolution and sensitivity, and its unique ability to determine the phosphorylation sites in a relatively direct fashion. However, the study of phosphorylated species by MS can still not be considered as trivial. The acidic phosphate group hinders the ionization of the molecule in positive ion mode MS. The lability of the phosphate bond leads to prompt fragmentation of the peptide [11-13]. In matrix assisted laser desorption ionization-time of flight (MALDI-TOF) MS, ion suppression effects further reduce the intensity of the peak of a 
phosphorylated species when analyzed with non phosphorylated ones $[14,15]$. Moreover, the in vivo phosphorylation rates are usually low and lead to low abundant species.

Several methods have been developed to facilitate the detection of phosphopeptides. The first strategy aims at selectively extracting phosphopeptides from a complex mixture using affinity chromatography methods, like immobilized metal affinity chromatography (IMAC) [16-18] and metal oxide chromatography (MOC) [19-21]. These two methods show important drawbacks, namely the nonspecific adsorption of acidic peptides on IMAC and MOC phases [22, 23] and the poor purification of basic phosphopeptides [24-27].

Another strategy is based on the chemical derivatization of phosphopeptides by $\beta$-elimination (BEM) of the phosphate group, leading to an unsaturated residue instead of the initial serine or threonine residue, dehydroalanine and $\beta$ methyldehydroalanine, respectively (Supplementary Information Figure S-1). Phosphotyrosine residues cannot be subjected to $\beta$-elimination reactions. The thus formed double bond can then be attacked through a Michael addition by a nucleophile bearing a moiety favorable to the MS analysis. This method was first proposed for the identification of glycosylations in proteins [28] before being extended to phosphorylated peptides and proteins [29].

The first step of the reaction is the removal of the phosphate group by $\beta$-elimination in basic conditions $(\mathrm{pH}>$ 11.5), which leads to a strong ionization enhancement. The reaction is catalyzed by group II metal ions, and particularly by barium(II) [30], accelerating the reaction and decreasing isomerization [31]. As such, the base used is commonly a saturated solution of barium hydroxide $\mathrm{Ba}(\mathrm{OH})_{2}$. It was also often suggested that adding organic solvent in the reaction medium makes the BEM more efficient. Among them, acetonitrile $(\mathrm{ACN})$, methanol $(\mathrm{MeOH})$, and dimethylsulfoxide (DMSO) are classically used, although less frequently for the last one, less compatible with MS analysis. However, the optimal quantity of organic solvent, and even the advantage it confers, is still under debate. Some authors advocate the use of $15 \%-30 \% \mathrm{ACN}$ or $\mathrm{MeOH}$ [32], others use a reaction mixture of $\mathrm{H}_{2} \mathrm{O}$, DMSO, and $\mathrm{MeOH}$ (8:3:1 in volume) [31, 33], while others do not see the need for aprotic solvents like DMSO [34] or even for organic solvent altogether [35]. H. E. Meyer et al. also noted that a percentage of organic solvent could protect the peptide [29]. Finally, the $\beta$-elimination is faster for phosphoserine residues than it is for phosphothreonine [31].

The $\beta$-elimination of the phosphate group leads to reactive species (enone types) that are usually further reacted by Michael addition upon attack of nucleophiles [36], such as amines or thiols, with a strong preference for the latter, more reactive $[31,37]$. Alcanethiols have been extensively used [29, 35, 36, 38-40], as well as dithiol, leaving a free thiol extremity to label the derivatized peptide with an affinity purification tag [38, 40-43]. Another effective strategy is to use a thiol substituted with a moiety that enhances the MS signal, like a protonable group [36, 44-46] or a pre-charged moiety, for example thiocholine [36, 37, 47]. Finally, in MALDI-TOF MS, it was observed that aromatic moieties or residues in a peptide improved its detection [14, 39, 48-50]. Nucleophiles substituted with aromatic moieties usually allow an intensity enhancement for the derivatized peptide $[32,51,52]$.

The two steps are usually quantitative, in relatively short times (a few hours). Increasing the reaction time often leads to secondary products, through isomerizations for example, and should be avoided [31]. Reported reaction temperatures stand between room temperature (RT) and $70{ }^{\circ} \mathrm{C}$. Appropriate time and temperature seem to strongly depend on the sequences of the peptides that are derivatized. The two steps ( $\beta$-elimination and Michael addition) can be performed simultaneously, when all the reagents are added together, or separately [32].

The major drawback of this derivatization method is a relative lack of selectivity of the $\beta$-elimination for the phosphorylated residues. The $O$-glycosylated residues lead to the same reaction [28], with a yield that seems much smaller than that of phosphoserine [30, 39]. More problematic, the cysteine residues are equally derivatized, with rates and yields comparable to that of phosphoserine residues [30]. The $\beta$-elimination on a cysteine residue generates a global loss of $\mathrm{H}_{2} \mathrm{~S}(-34$ u.) and, as with a phosphoserine residue, leads to the formation of a dehydroalanine residue which is thus a Michael acceptor. In the majority of studies, cysteine residues are therefore protected, either by acid performic oxidation [40] or by reductive alkylation (iodoacetamide) [53]. It is commonly accepted that this is a sufficient protection and that if derivatization on cysteine residues is still observed, it comes from an incomplete protection rather than a derivatization on protected cysteines $[36,45,51]$. One study observed a $\beta$-elimination on an alkylated cysteine [52]. $\beta$-Elimination on unphosphorylated serine or threonine residues are usually not observed [29, $30]$, but the possibility is considered by some authors [35, 36] and was already reported, even though it is much less efficient than on phosphorylated residues [42, 54]. This would for example prevent the comparison of two phosphoproteomes obtained in different experimental conditions.

Furthermore, the derivatization efficiency seems to largely depend on the peptide sequence to derivatize. The reaction is much faster with phosphoserine residues [31, 34] than it is for phosphothreonines. A weaker reactivity of phosphorylation sites next to a proline residue [51] or preceding a glutamic, aspartic acid, or the C-terminus [36] was observed. It is therefore difficult to state universal experimental conditions that would suit all phosphopeptides [32]. This announces foreseeable risks when working on a complex or unknown sample. Furthermore, the Michael addition on the dehydroamino acid followed by reprotonation of the $\alpha$-center is not stereospecific, leading to a mixture of diastereoisomers [30]. It is possible for the stereoisomers to be separated by HPLC, which will lead to losses in signal intensity in the case of LC-MS analysis [35]. 
The goal of the study presented here is to apply the $\beta$ elimination strategy alone on a phosphorylated peptide that is hardly purified by $\mathrm{TiO}_{2}$ or IMAC enrichment procedures, mostly because of its high basicity [25]. In view of this difficulty, $\beta$-elimination was chosen as an alternative strategy to improve the detection of this specific phosphopeptide. This peptide, biot-pAdd, is derived from the protein adducin, whose activity is regulated by protein kinase $\mathrm{C}$ (PKC) serine phosphorylation. The biot-Add peptide was designed as a substrate of the PKC for in vivo kinase activity studies. The sequence of the phosphopeptide is biotin$\mathrm{G}_{4} \mathrm{CFRTP}_{\mathrm{p}} \mathrm{SFLKK}-\mathrm{NH}_{2}$. The natural sequence starts at the first $\mathrm{F}$ from the $\mathrm{N}$-terminus. A biotin tag was added for purification purposes, and the four $G$ residues serve as spacer. A cysteine residue was also added for coupling of the PKC substrate to vectors in order to carry the biot-Add peptide into living cells. The presence of the biotin tag is not favorable for ionization and further increases the need to improve the detection of this phosphopeptide.

Since the targeted experiments are in cellulo phosphorylations, the lysates obtained after internalization into the cytosol are a mixture of phosphorylated (biot-pAdd) and unphosphorylated (biot-Add) peptides, probably with a large excess of the latter. We thus evaluated the $\beta$-elimination strategy on the two separated forms of the peptide as well as on mixtures of both. Optimizations of the experimental conditions were performed, especially with regards to the reaction time, temperature and solvent, and to the nature and concentration of the base that was used. Since this type of peptide sequence is not easily studied by classical phosphoproteomics tools such as IMAC and MOC, the need to develop alternative tools is crucial. However, it presents several features that will also make the BEM reaction more challenging. In particular, the proline residue next to the phosphorylation site will probably hamper the reaction [51], and the cysteine residue will be highly susceptible to secondary reactions. This study was thus restricted to this particularly challenging sequence. The difficulties to optimally tune the reaction conditions are underlined, as well as the attention that must be paid to secondary reactions.

\section{Experimental}

\section{Materials}

$\alpha$-Cyano-4-hydroxycinnamic acid (CHCA) was from Sigma (Saint Quentin Villavier, France). Acetonitrile (ACN) HPLCgrade was from VWR Prolabo (Fontenay sous bois, France), deionized water $(18.4 \mathrm{M} \Omega . \mathrm{cm})$ was obtained from an Elga PURELAB Classic. Poros Oligo R3 reverse-phase material was from PerSeptive Biosystems (Foster City, California, US). GELoader Tips and all the plastic tubes were from Eppendorf.

\section{Fmoc Synthesis of the Peptides}

The peptides used in the study (biot-Add: biotin-GGGGCFR

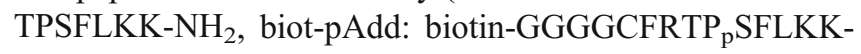

$\mathrm{NH}_{2}$ ) were synthesized by Dr. C. Piesse, (Plateforme d'Ingénierie des protéines, IFR 83, UPMC, France), as described previously [55]. Purity of the peptides was assessed by analytical RP-HPLC and MALDI-TOF MS and was found to be $>95 \%$.

\section{$\beta$-Elimination}

A solution of $\mathrm{Ba}(\mathrm{OH})_{2}$ or $\mathrm{CsOH}$, saturated or at the chosen concentration, was prepared in the desired solvent $\mathrm{S}\left(\mathrm{H}_{2} \mathrm{O}\right.$, ACN $30 \%$ or ACN $50 \%$ ). Stock solutions of the peptide in $\mathrm{H}_{2} \mathrm{O}\left(10^{-3} \mathrm{M}\right)$ were diluted in $\mathrm{S}$ in order to have the desired concentration in $2 \mu \mathrm{L}$. This solution is called $\mathrm{P}_{\mathrm{d}}$. The reaction was performed in $20 \mu \mathrm{L}$ of S to which $2 \mu \mathrm{L}$ of $\mathrm{P}_{\mathrm{d}}$ were added. For a kinetic study with n sampling of $20 \mu \mathrm{L}$, the reaction was performed in $n \times 20 \mu \mathrm{L}$ of S with $n \times 2 \mu \mathrm{L}$ of $\mathrm{P}_{\mathrm{d}}$. The $\beta$-elimination reaction was performed at the chosen temperature $\left(4{ }^{\circ} \mathrm{C}\right.$, RT, $37{ }^{\circ} \mathrm{C}$, or $\left.50{ }^{\circ} \mathrm{C}\right)$ and for the chosen time (a few minutes up to $4 \mathrm{~h} 30 \mathrm{~min}$ ) and stopped by addition of $10 \mu \mathrm{L}$ of formic acid (FA) $100 \%$ for each $20 \mu \mathrm{L}$ sampling (final FA concentration $\approx 30 \%$ ). When S contained $\mathrm{ACN}$, the vials were left open at room temperature for $1-2 \mathrm{~h}$ to allow evaporation of the organic solvent. In all cases a desalting step was performed.

\section{Desalting and Concentration of the Samples}

Microcolumns packed with Poros oligo R3 resin were prepared as described previously [56]. The bound peptides were eluted directly onto the MALDI target using $0.6 \mu \mathrm{L}$ of the desired matrix solution.

\section{Alkylation of the Cysteine Residue and $\beta$-Elimination}

The cysteine alkylation was performed on 50 pmol of peptide. To $20 \mu \mathrm{L}$ of $\mathrm{NH}_{4} \mathrm{HCO}_{3} 50 \mathrm{mM}(\mathrm{pH} 8)$ were added $5 \mu \mathrm{L}$ of peptide solution in $\mathrm{H}_{2} \mathrm{O}\left(10^{-5} \mathrm{M}\right)$ and $5 \mu \mathrm{L}$ of dithiothreitol (DTT) $45 \mathrm{mM}$ in $\mathrm{NH}_{4} \mathrm{HCO}_{3} 50 \mathrm{mM}$ (pH8) in order to reduce potential disulfide bridges. The mixture was incubated for $15 \mathrm{~min}$ at $50{ }^{\circ} \mathrm{C}$ and cooled down to room temperature. Five $\mu \mathrm{L}$ of iodoacetamide $100 \mathrm{mM}$ in $\mathrm{NH}_{4} \mathrm{HCO}_{3} 100 \mathrm{mM}$ were added, and the mixture was further incubated for $15 \mathrm{~min}$ at room temperature in the dark. The reaction mixture was acidified by addition of $3.5 \mu \mathrm{L}$ FA $(100 \%)$ and desalted as stated previously. The bound peptides were eluted with $2 \mu \mathrm{L}$ of $50 \%$ ACN. The BEM reaction was then performed according to the protocol described previously.

\section{Mass Spectrometry}

CHCA (5 mg.mL ${ }^{-1}$ ) was dissolved in $50 \% \mathrm{ACN}, 50 \% \mathrm{H}_{2} \mathrm{O}$ containing $0.1 \%$ TFA. The dried droplet method for target preparation was chosen. Positive and negative ion MALDITOF as well as positive ion MALDI-TOF-TOF mass spectra 
were recorded on the Applied Biosystems (Framingham, MA 01701, USA) 4700 Proteomics Analyzer instrument. MALDI-TOF MS was performed in reflector mode (focus mass at $1800 \mathrm{u}$ ) near the threshold of laser fluence. Calibration was performed using external standards (Proteomix 4 from LaserBio Labs (Valbonne, France)). MALDI-TOF-TOF experiments were carried out in CID mode with gas $\left(\mathrm{N}_{2}, \sim 2 \times\right.$ $10^{-6}$ Torr) with collision energy of $1 \mathrm{keV}$. Typically the precursor ion $[\mathrm{M}+\mathrm{H}]^{+}$was selected in a window $(-5 \mathrm{u}, 5 \mathrm{u})$ centered on the first isotope. Data Explorer ver. 4.6 software was used to analyze the spectra.

\section{Results and Discussion}

The behavior of the phosphopeptide biot-pAdd as well as of its non phosphorylated counterpart biot-Add with regards to $\beta$-elimination will be discussed.

\section{$\beta$-Elimination on biot-pAdd and biot-Add in $\mathrm{H}_{2} \mathrm{O}$ at $37{ }^{\circ} \mathrm{C}$}

The $\beta$-elimination reaction was performed on the synthetic peptides biot-pAdd and biot-Add in an aqueous solvent saturated with $\mathrm{Ba}(\mathrm{OH})_{2}$ at $37^{\circ} \mathrm{C}$ for $1 \mathrm{~h}$. Representative spectra are shown in Figure 1. Direct MALDI-TOF analysis of biotpAdd $\left([\mathrm{M}+\mathrm{H}]^{+}\right.$at $m / z 1759.8$, Figure 1a showed the presence of deletion peptides, impurities arising from the peptide synthesis that could not be fully eliminated by HPLC purification. The sequences of these peptides are Ac-GCFRTP $\mathrm{SFLKK}-\mathrm{NH}_{2}$ $\left([\mathrm{M}+\mathrm{H}]^{+}\right.$at $\left.m / z 1404.7\right)$ and Ac-FRTP SFLKK-NH $_{2}\left([\mathrm{M}+\mathrm{H}]^{+}\right.$ at $m / z 1244.6)$ as indicated by $\mathrm{MS} / \mathrm{MS}$ experiments. After $\beta$-elimination (Figure $1 \mathrm{~b}$ and $\mathrm{d}$ ), we would expect the phosphorylated peptide biot-pAdd to be converted into a single product at $m / z 1661.8$ (-98 u.) and the non phosphorylated peptide biot-Add to remain unmodified. However, the Figure 1 clearly shows several products.

On the biot-pAdd peptide (Figure $1 \mathrm{~b}$ ), the $\beta$-elimination of $\mathrm{H}_{3} \mathrm{PO}_{4}$ was observed, leading to the most intense ion at $\mathrm{m} / \mathrm{z} 1661.8$. From now on, this species will be referred to as $\left\{-\mathrm{H}_{3} \mathrm{PO}_{4}\right\}$ biot-pAdd. The reaction was not complete, as shown by the persistence of a low intensity signal at $\mathrm{m} / \mathrm{z}$ 1759.8. The major secondary reaction was the expected $\beta$ elimination of the sulfhydryl group on the cysteine residue, leading to mass losses of $34 \mathrm{u}\left(-\mathrm{H}_{2} \mathrm{~S}\right)$. The corresponding products are the $[\mathrm{M}+\mathrm{H}]^{+}$at $m / z 1725.8\left(-\mathrm{H}_{2} \mathrm{~S}\right)$ and $m / z$ $1627.8\left(-\mathrm{H}_{2} \mathrm{~S}\right.$ and $\left.-\mathrm{H}_{3} \mathrm{PO}_{4}\right)$. Similar reactions were observed on the deletion peptides: $\mathrm{H}_{3} \mathrm{PO}_{4}$ elimination on the $[\mathrm{M}+\mathrm{H}]^{+}$ at $m / z 1244.7$ leading to the $[\mathrm{M}+\mathrm{H}]^{+}$at $m / z 1146.7 ; \mathrm{H}_{3} \mathrm{PO}_{4}$ elimination on the $[\mathrm{M}+\mathrm{H}]^{+}$at $\mathrm{m} / z 1404.7$ leading to the $[\mathrm{M}+\mathrm{H}]^{+}$at $m / z 1306.7 ; \mathrm{H}_{3} \mathrm{PO}_{4}$ and $\mathrm{H}_{2} \mathrm{~S}$ elimination on the $[\mathrm{M}+\mathrm{H}]^{+}$at $\mathrm{m} / z 1404.7$ leading to the $[\mathrm{M}+\mathrm{H}]^{+}$at $\mathrm{m} / z$ 1272.7. In addition to that, many peaks in the $1200<\mathrm{m} / \mathrm{z}<$ 1500 range were observed, that will be termed degradation peptides. They correspond to successive losses of the biotin tag and of the following four glycine residues, with potential $\mathrm{H}_{3} \mathrm{PO}_{4}$ and/or $\mathrm{H}_{2} \mathrm{~S}$ eliminations. The sequences of the products observed were checked by MALDI-TOF-TOF and are summarized in Supplementary Information Table S-1. These products can be explained either by in-solution reactions or by in-source prompt fragmentations. In solution, the biotin end could be particularly reactive in these experimental conditions, and its loss would result in a weakening of the N-terminal. A particular reactivity of the biotin end arose from the following observations: two analogs of the peptide pair biot-Add and biot-pAdd were also studied. The first one, Add-biot (and pAdd-biot), has the following sequence:

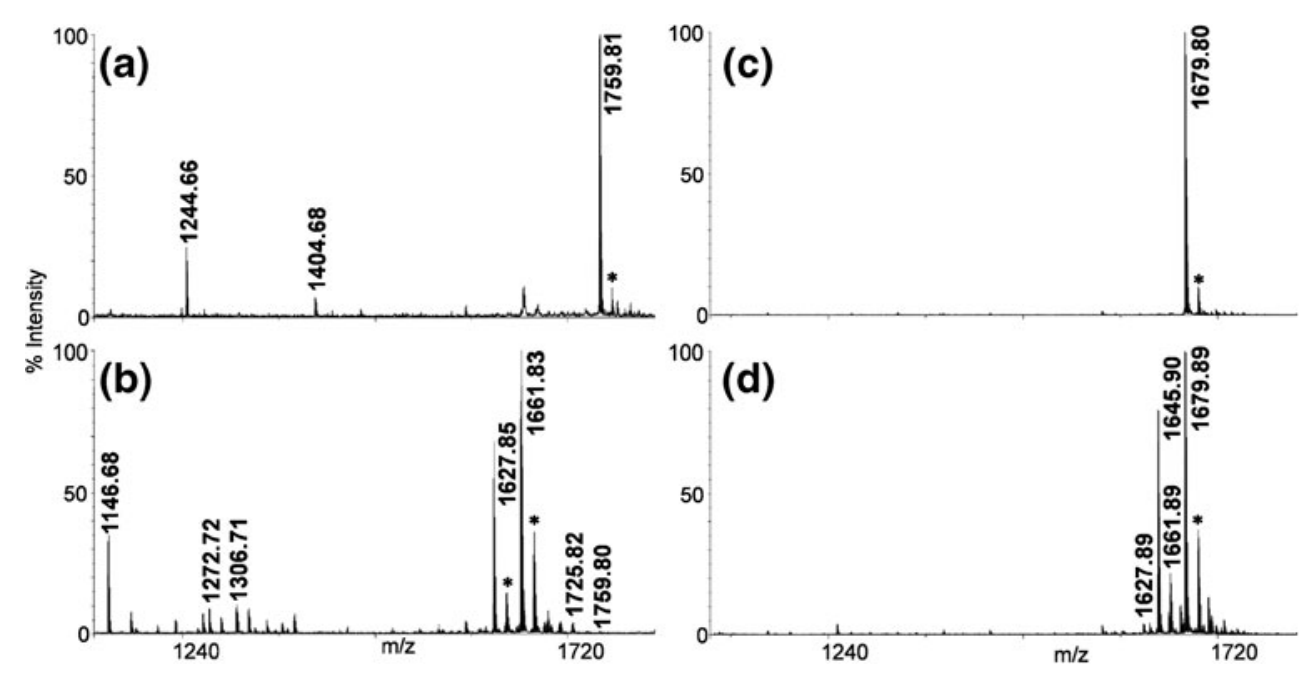

Figure 1. Positive ion reflector MALDI-TOF analysis with CHCA as a matrix of the peptides biot-pAdd $\left([\mathrm{M}+\mathrm{H}]^{+}\right.$at $\left.m / z 1759.8\right)$ (a), (b) and biot-Add ([M $+\mathrm{H}]^{+}$at $\left.m / z 1679.8\right)$ (c), (d). (a), (c) Direct analysis of the two peptides alone (1 pmol on target) and (b), (d) after a $\beta$-elimination reaction in $\mathrm{H}_{2} \mathrm{O}$ saturated in $\mathrm{Ba}(\mathrm{OH})_{2}$ for $1 \mathrm{~h}$ at $37{ }^{\circ} \mathrm{C}$ on 20 pmol of the two peptides alone. The peptides at $m / z 1244.7$ and 1404.7 are deletion peptides arising from the solid-phase synthesis of biot-pAdd. The peptides marked with * result from oxidations 
Ac-CFRTP ${ }_{(\mathrm{p})} \mathrm{SFLKKG}_{4}-\left(\mathrm{NH}-\left(\mathrm{CH}_{2}\right)_{2}-\mathrm{NH}\right)$-biotin. The PKC substrate sequence is the same, but the biotin tag and the four Gly residues have been transferred to the $\mathrm{C}$-terminus, with the additional spacer $\left(\mathrm{NH}-\left(\mathrm{CH}_{2}\right)_{2}-\mathrm{NH}\right)$. The second analog, $\operatorname{biot}\left(\mathrm{O}_{2}\right) \mathrm{E}_{2}$-Add (and $\operatorname{biot}\left(\mathrm{O}_{2}\right) \mathrm{E}_{2}$-pAdd), has the following sequence: biotin $\left(\mathrm{O}_{2}\right) \mathrm{EG}_{4} \mathrm{ECFRTP}_{(\mathrm{p})} \mathrm{SFLKK}_{\mathrm{NH}}$. The PKC substrate sequence is again the same, with the biotin tag and the four Gly residues at the N-terminus, but with two additional Glu residues on both sides of the four Gly residues. On these analogs, we also observed successive losses of the biotin tag and the consecutive 4-5 residues, regardless of their position on the sequence $(\mathrm{N}$-terminus or C-terminus) or of the fact that the four Gly are directly next to the biotin or separated by a Glu residue or the additional $\left(\mathrm{NH}-\left(\mathrm{CH}_{2}\right)_{2}-\mathrm{NH}\right)$ spacer. The other terminus is never particularly reactive. Regarding possible in-source prompt fragmentations, these peptides with the biotin- $\mathrm{G}_{4}$ tag fragment very easily in MALDI-TOF-TOF mode (CID activation) at these same positions, showing a susceptibility of these sites to fragmentation, probably thanks to the relatively high proton affinity of the biotin. However, these products were not detected on the spectra before BEM and their intensity increased with the reaction time, seemingly indicating that in-source prompt fragmentation is not the explanation. Moreover, the laser intensity was used near the threshold of the fluence necessary to obtain a signal in order to minimize fragmentation during the MALDI-TOF analysis.

On the peptide biot-Add (Figure 1d), abundant $\mathrm{H}_{2} \mathrm{~S}$ elimination was observed, leading to the $[\mathrm{M}+\mathrm{H}]^{+}$at $\mathrm{m} / \mathrm{z}$ 1645.8. More surprisingly, $\mathrm{H}_{2} \mathrm{O}$ elimination on the nonphosphorylated serine residue also occurred, leading to the $[\mathrm{M}+\mathrm{H}]^{+}$at $m / z 1661.8\left(-\mathrm{H}_{2} \mathrm{O}\right)$ and $1627.8\left(-\mathrm{H}_{2} \mathrm{O}\right.$ and $\mathrm{H}_{2} \mathrm{~S}$ ). These two products are identical to the ones obtained after $\mathrm{H}_{3} \mathrm{PO}_{4}$ elimination and $\mathrm{H}_{3} \mathrm{PO}_{4}$ and $\mathrm{H}_{2} \mathrm{~S}$ elimination on biot-pAdd. Less intense degradation peptides starting from the biotin side were also observed.

\section{Protection of the Cysteine Residue by Alkylation}

As was amply suggested in the literature, reductive alkylation with iodoacetamide was performed on the cysteine residue in order to prevent $\mathrm{H}_{2} \mathrm{~S}$ elimination. The alkylation reaction was tested on an equimolar mixture of biot-Add $(\mathrm{m} / \mathrm{z} 1679.8)$ and biot-pAdd $(\mathrm{m} / \mathrm{z} 1759.8)$ and analyzed by MALDI-TOF MS (Figure 2b). The cysteine residue was properly alkylated on both peptides, leading the corresponding species at $+57 \mathrm{u}, \mathrm{m} / z 1736.9$ for biot-Add and $\mathrm{m} / \mathrm{z} 1816.9$ for biot-pAdd. The reaction was not complete as shown by the persistence of low intensity signals corresponding to the non alkylated forms, but these species were really minor in the MALDI-TOF spectrum. BEM was then performed on the alkylated mixture (Figure 2c). The expected products corresponding to the unmodified alkylated biot-Add $(\mathrm{m} / \mathrm{z} 1736.9)$ and to the alkylated biot-pAdd

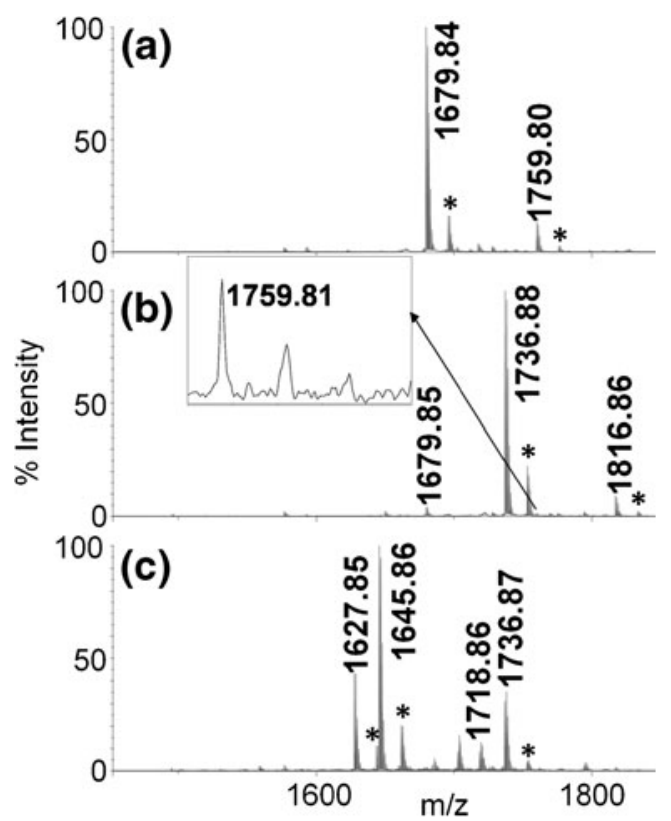

Figure 2. Positive ion reflector MALDI-TOF analysis with $\mathrm{CHCA}$ as a matrix of an equimolar mixture between biot-Add $\left([\mathrm{M}+\mathrm{H}]^{+}\right.$at $\left.m / z 1679.8\right)$ and biot-pAdd $\left([\mathrm{M}+\mathrm{H}]^{+}\right.$at $m / z$ 1759.8). (a) Direct analysis of the mixture (1 pmol of total peptide on target), (b) after alkylation of the cysteine residues on $50 \mathrm{pmol}$ of the mixture where the biot-pAdd $[\mathrm{M}+\mathrm{H}]^{+}$at $m / z$ 1759.8 is magnified in the inset and (c) after alkylation of the cysteine residues followed by $\beta$-elimination reaction in $\mathrm{H}_{2} \mathrm{O}$ saturated in $\mathrm{Ba}(\mathrm{OH})_{2}$ for $1 \mathrm{~h}$ at $37^{\circ} \mathrm{C}$ on 50 pmol of the mixture. The peptides marked with * result from oxidations

with $\mathrm{H}_{3} \mathrm{PO}_{4}$ elimination $(m / z 1718.9)$ were observed on the spectrum.

However, the most intense peaks at $m / z 1645.9$ and 1627.9 were already present on the Figure $1 \mathrm{c}$. The species at $m / z 1645.9$ arises from the alkylated form of biot-Add and was formed by BEM on its alkylated cysteine residue, leading to a global loss of $\mathrm{HSCH}_{2} \mathrm{CONH}_{2}(-91 \mathrm{u}$ ) (Supplementary Information Figure S-2). The species at $m / z 1627.9$ arises either from the alkylated form of biot-Add (double elimination of $\mathrm{HSCH}_{2} \mathrm{CONH}_{2}[-91 \mathrm{u}]$ and of $\mathrm{H}_{2} \mathrm{O}[-18 \mathrm{u}]$ ) or from the alkylated form of biot-pAdd (double elimination of $\mathrm{HSCH}_{2} \mathrm{CONH}_{2}[-91 \mathrm{u}]$ and of $\mathrm{H}_{3} \mathrm{PO}_{4}[-98 \mathrm{u}]$ ). As shown in Figure $2 \mathrm{~b}$, although the alkylation reaction was not complete, the unprotected peptides were minor in the MALDI-TOF spectrum. The high abundance of the products at $m / z 1645.9$ and 1627.9 after alkylation and BEM (Figure 2c) can only be explained if the cysteine alkylation was not sufficient to protect the cysteine residues from $\beta$ elimination in these experimental conditions.

\section{Rate of the $\mathrm{H}_{3} \mathrm{PO}_{4}$ Elimination under Different Experimental Conditions}

The impact of modifying the experimental conditions of the BEM was evaluated on the peptides biot-Add and biotpAdd. The reaction solvent was either $\mathrm{H}_{2} \mathrm{O}$ or $30 \% \mathrm{ACN}$. 
The reaction temperature was $4{ }^{\circ} \mathrm{C}$, room temperature (RT, $\approx 25{ }^{\circ} \mathrm{C}$ ), $37{ }^{\circ} \mathrm{C}$, or $50{ }^{\circ} \mathrm{C}$. A kinetic study was performed, with reaction times varying from a few minutes to $4 \mathrm{~h} 30 \mathrm{~min}$. The first parameter studied was the $\beta$-elimination of the phosphate group on the peptide biot-pAdd (loss of $\mathrm{H}_{3} \mathrm{PO}_{4},-98 \mathrm{u}$ ). In order to quantitatively evaluate this reaction, the area of the peak corresponding to the peptide biot-pAdd $\left([\mathrm{M}+\mathrm{H}]^{+}\right.$at $\left.m / z 1759.8\right)$ was extracted from the MALDI-TOF spectra acquired under the experimental conditions stated before. This area was normalized with the sum of the areas of all the peaks present on the spectrum. For each species, the area of the peak corresponds to the sum of the whole isotopic pattern. The same treatment was performed on $\left\{-\mathrm{H}_{3} \mathrm{PO}_{4}\right\}$ biot-pAdd $\left([\mathrm{M}+\mathrm{H}]^{+}\right.$at $\left.m / z 1661.8\right)$.

Figure 3 shows the relative area of the biot-pAdd peptide (Figure 3a) and of the $\left\{-\mathrm{H}_{3} \mathrm{PO}_{4}\right\}$ biot-pAdd peptide (Figure 3b) as a function of the reaction time for the two reaction solvents $\left(\mathrm{H}_{2} \mathrm{O}\right.$ in black, $30 \% \mathrm{ACN}$ in grey) and the four reaction temperatures. The standard deviations of these measurements are not shown on the Figure 3 as they complicate the figure. They are reported in Supplementary Information Figure S-3 to S-6. It should be noted that these standard deviations are high, showing that the reaction is not very reproducible. As was expected, modifying the reaction temperature clearly had an impact on the rate of the reaction. At $4{ }^{\circ} \mathrm{C}$, even after $4 \mathrm{~h} 30 \mathrm{~min}$, the biot-pAdd peptide remained abundant $(\approx 30 \%$ of the spectrum). At the three other temperatures, the biot-pAdd peptide could be fully eliminated. The reaction rate increased with the temperature. Regarding the effect of solvents, if the use of $30 \% \mathrm{ACN}$ has been reported to increase the rate of the $\mathrm{H}_{3} \mathrm{PO}_{4}$ elimination on phosphorylated peptides, we did not observe such an improvement here. Indeed, at $50^{\circ} \mathrm{C}$ and $37^{\circ} \mathrm{C}$, the reaction rate was similar in $\mathrm{H}_{2} \mathrm{O}$ and in $30 \% \mathrm{ACN}$, whereas it was in fact lower in $30 \% \mathrm{ACN}$ at RT and $4{ }^{\circ} \mathrm{C}$.

\section{Secondary Reactions under Different Experimental Conditions}

Figure $3 \mathrm{~b}$ shows that the disappearance of the biot-pAdd peptide is not correlated only with the appearance of $\left\{-\mathrm{H}_{3} \mathrm{PO}_{4}\right\}$ biot-pAdd. The secondary reactions mentioned earlier also occurred. In most of the experimental conditions tested, the relative area of $\left\{-\mathrm{H}_{3} \mathrm{PO}_{4}\right\}$ biot-pAdd decreased with time after a maximum, except when the reaction was performed at $4{ }^{\circ} \mathrm{C}$ or at room temperature in $30 \% \mathrm{ACN}$. In Figure $3 \mathrm{~b}$, a striking difference between $\mathrm{H}_{2} \mathrm{O}$ and $30 \%$ $\mathrm{ACN}$ as a solvent was this time observed, the relative area of $\left\{-\mathrm{H}_{3} \mathrm{PO}_{4}\right\}$ biot-pAdd being consistently higher in the latter. As showed by Figure 3a, this observation should not be mistaken with a higher reaction rate.

From Figure 3, we selected the condition where $30 \%$ $\mathrm{ACN}$ is used at room temperature as being the best compromise between the reaction rate (Figure $3 \mathrm{a}$ ) and the relative abundance of secondary reactions (Figure $3 \mathrm{~b}$ ). Indeed, $30 \% \mathrm{ACN}$ at $4{ }^{\circ} \mathrm{C}$ and at room temperature are the only conditions were the relative area of $\left\{-\mathrm{H}_{3} \mathrm{PO}_{4}\right\}$ biotpAdd does not decrease with time after a maximum. Moreover, the reaction rate is much higher at room temperature, which also allows for the highest relative abundance of $\left\{-\mathrm{H}_{3} \mathrm{PO}_{4}\right\}$ biot-pAdd. On the contrary, performing the reaction in $\mathrm{H}_{2} \mathrm{O}$ at $37^{\circ} \mathrm{C}$ allows for a faster kinetic, but a low abundant $\left\{-\mathrm{H}_{3} \mathrm{PO}_{4}\right\}$ biot-pAdd product. These two contrasted experimental conditions were thus chosen to be further examined.

Figure 4 is centered on these two conditions, $30 \% \mathrm{ACN}$ as a solvent at room temperature and $\mathrm{H}_{2} \mathrm{O}$ as a solvent at $37^{\circ} \mathrm{C}$, for the peptides biot-pAdd and biot-Add separately. For biot-pAdd (Figure $4 \mathrm{a}$ and $\mathrm{c}$ ), the selected peaks of interest were biot-pAdd (namely $m / z 1759.8$ ), $\left\{-\mathrm{H}_{3} \mathrm{PO}_{4}\right\}$ biotpAdd (namely $\mathrm{m} / \mathrm{z} 1661.8$ ) and the sum of the secondary
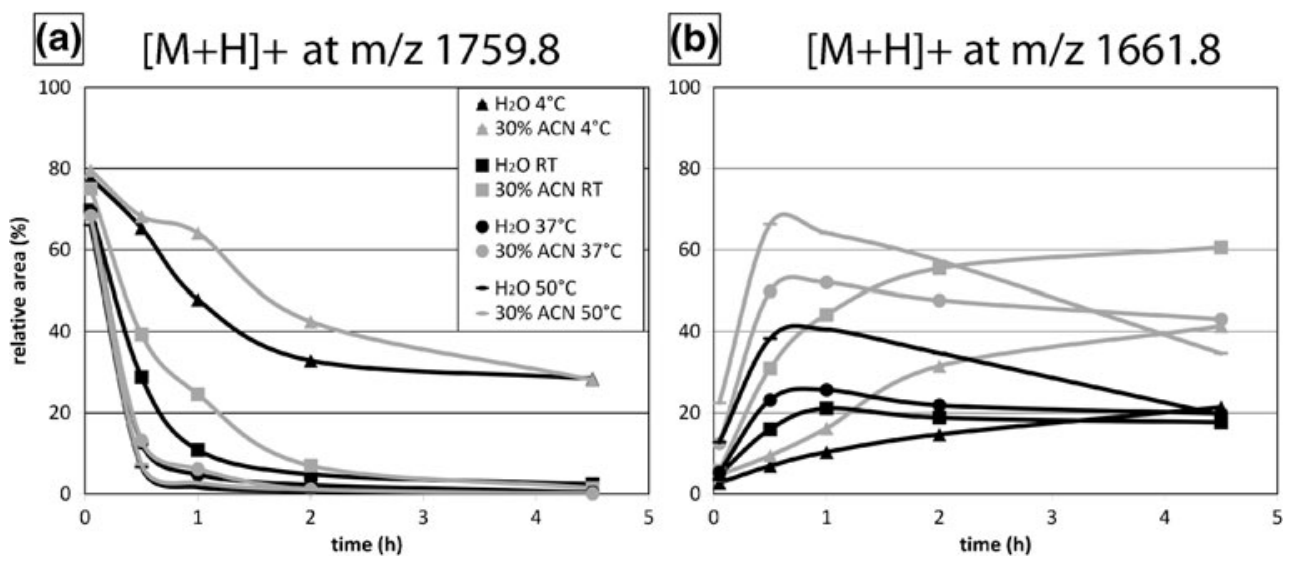

Figure 3. Comparison of (a) the kinetic of disappearance of the biot-pAdd peptide $\left([\mathrm{M}+\mathrm{H}]^{+}\right.$at $\left.m / z 1759.8\right)$ and (b) the kinetic of production of the $\left\{-\mathrm{H}_{3} \mathrm{PO}_{4}\right\}$ biot-pAdd peptide $\left([\mathrm{M}+\mathrm{H}]^{+}\right.$at $\left.m / z 1661.8\right)$ during $\beta$-elimination in different experimental conditions. The figure shows the relative areas of the two peaks of interest, extracted from positive ion reflector MALDI-TOF spectrum, with CHCA as a matrix, normalized by the sum of the areas of all the species present on the spectrum. The whole isotopic patterns are taken into account. The experimental conditions are: $\mathrm{H}_{2} \mathrm{O}$ (black) or $30 \%$ ACN (grey) as a solvent with different temperature conditions: $4^{\circ} \mathrm{C}$ (triangles), room temperature (squares), $37^{\circ} \mathrm{C}$ (circles), and $50{ }^{\circ} \mathrm{C}$ (lines) as a temperature 


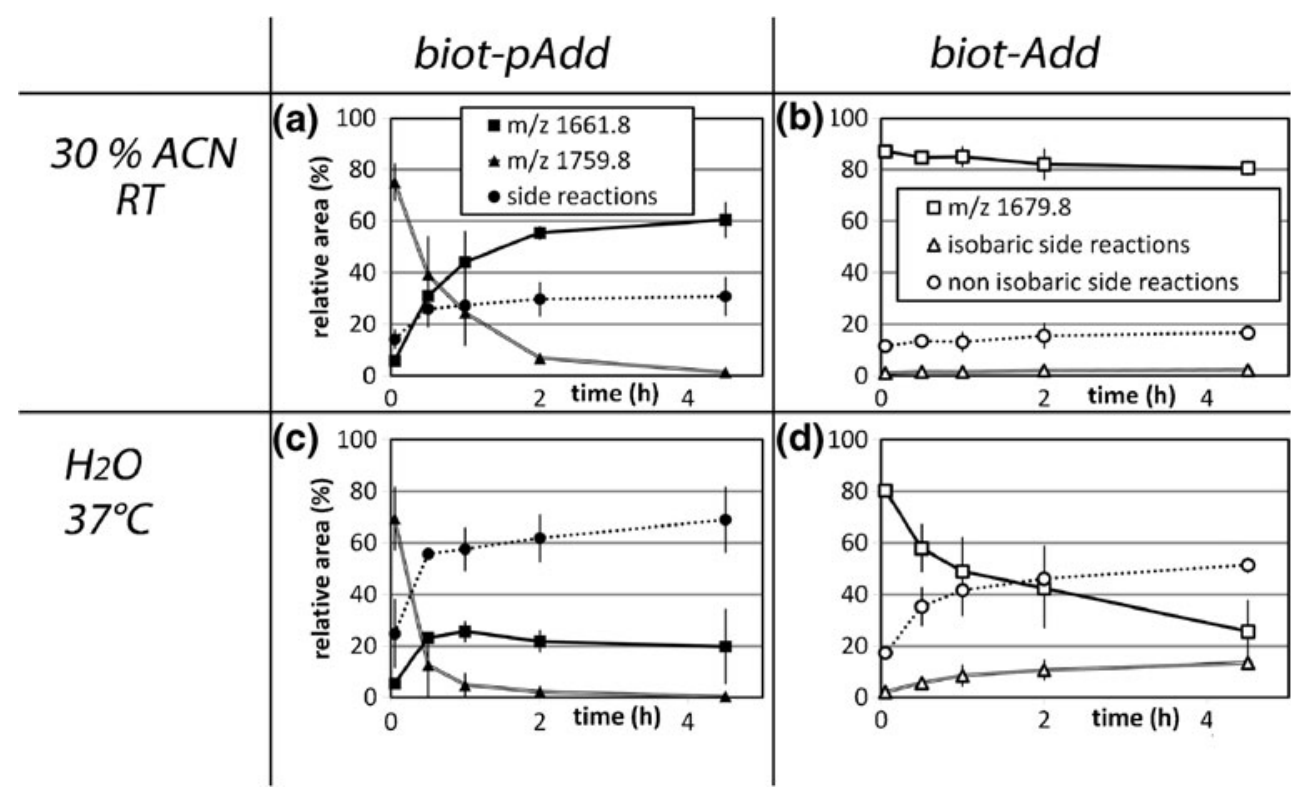

Figure 4. Positive ion reflector MALDI-TOF analysis with CHCA as a matrix of the relative areas of the peaks obtained during the kinetic study of the $\beta$-elimination reaction on 20 pmol of biot-pAdd (a), (c) and biot-Add (b), (d). The reaction is performed in $30 \% \mathrm{ACN}$ saturated in $\mathrm{Ba}(\mathrm{OH})_{2}$ at room temperature (a), (b) and $\mathrm{H}_{2} \mathrm{O}$ saturated in $\mathrm{Ba}(\mathrm{OH})_{2}$ at $37{ }^{\circ} \mathrm{C}$ (c), (d). The peaks of interest are (i) for biot-pAdd: biot-pAdd at $m / z 1759.8$ (black triangle), $\left\{-\mathrm{H}_{3} \mathrm{PO}_{4}\right\}$ biot-pAdd at $m / z 1661.8$ (black squares), and the sum of the side reactions (black circles); (ii) for biot-Add: biot-Add at $m / z 1679.8$ (white squares), the sum of the isobaric side reactions (white triangles), and the sum of the non isobaric side reactions (white circles)

reactions (namely side reactions). For biot-Add (Figure $4 \mathrm{~b}$ and d), the selected peaks of interest were biot-Add (namely $\mathrm{m} / \mathrm{z} 1679.8$ ), the sum of the secondary reactions giving products identical to the ones obtained with biot-pAdd (namely isobaric side reactions) and the sum of the secondary reactions giving products that could be distin-

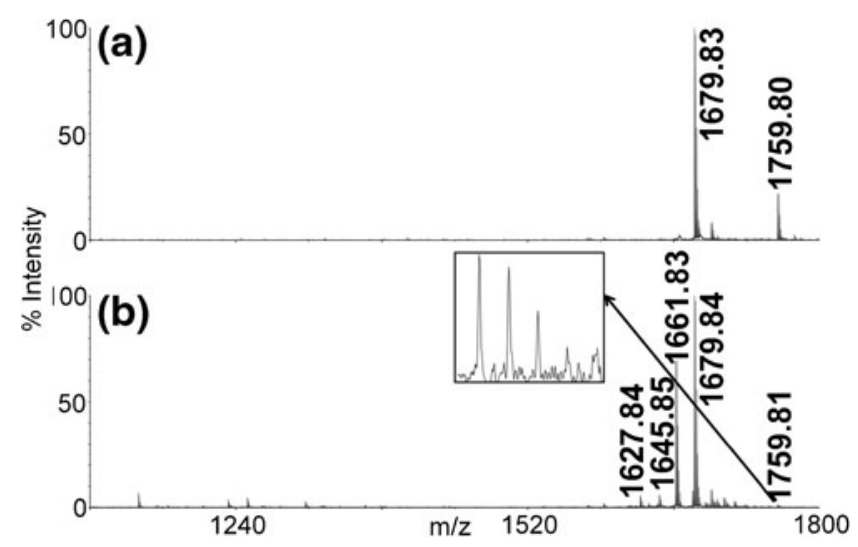

Figure 5. Positive ion reflector MALDI-TOF analysis with CHCA as a matrix of an equimolar mixture of biot-Add ([M + $\mathrm{H}]^{+}$at $\left.m / z 1679.8\right)$ and biot-pAdd $\left([\mathrm{M}+\mathrm{H}]^{+}\right.$at $\left.m / z 1759.8\right)$. (a) Direct analysis of the mixture (1 pmol total peptide on target) and (b) after $\beta$-elimination reaction on 20 pmol of the mixture in $30 \% A C N$ saturated in $\mathrm{Ba}(\mathrm{OH})_{2}$ for $4 \mathrm{~h}$ at room temperature guished from the ones coming from biot-pAdd (namely nonisobaric side reactions). The already noted difference between these experimental conditions was again obvious. In $\mathrm{H}_{2} \mathrm{O}$ at room temperature (Figure $4 \mathrm{c}$ and d), the biot-pAdd peptide disappeared fairly rapidly, but the area of $\left\{-\mathrm{H}_{3} \mathrm{PO}_{4}\right\}$ biot-pAdd remained inferior to the sum of the secondary reactions. For the non phosphorylated peptide, the situation was even worse since the relative area of biot-Add decreased rapidly; the isobaric side reactions were fairly abundant in the spectrum, while they must be suppressed for working with a mixture of the phosphorylated and non phosphorylated forms. Working in $30 \% \mathrm{ACN}$ at room temperature dramatically increased the selectivity of the reaction towards the elimination of $\mathrm{H}_{3} \mathrm{PO}_{4}$. The $\left\{-\mathrm{H}_{3} \mathrm{PO}_{4}\right\}$ biot-pAdd peptide was this time the most intense species in the spectrum after $1 \mathrm{~h}$, and the biotpAdd peptide was fully eliminated after $4 \mathrm{~h} 30 \mathrm{~min}$. For the biot-Add peptide, the secondary reactions, and in particular the isobaric ones, were this time strongly minimized.

Other experimental conditions were tested but did not improve these results. Using $30 \% \mathrm{ACN}$ as a solvent, the concentration of the base $\mathrm{Ba}(\mathrm{OH})_{2}$ was decreased from saturated conditions $(\approx 0.1 \mathrm{M})$ to $5 \mathrm{mM}$. This proved detrimental to the selectivity of the BEM since it favored side reactions. $\mathrm{CsOH}$ was also used as a base, from $0.1 \mathrm{M}$ up to $10 \mathrm{M}$, with no improvement either. Finally, going from $30 \% \mathrm{ACN}$ to $50 \% \mathrm{ACN}$ in the reaction solvent did not notably modify the outcome in terms of reaction rate and side reactions abundance. 


\section{Improvement of the Ionization Efficiency}

For these peptide sequences, the optimal experimental conditions for the BEM were thus the use of $30 \% \mathrm{ACN}$ saturated in $\mathrm{Ba}(\mathrm{OH})_{2}$ at room temperature for $4 \mathrm{~h}$. The reaction was performed on an equimolar mixture of biotAdd and biot-pAdd. This mixture was first analyzed directly (Figure 5a), showing a strong imbalance of ionization efficiencies in disfavor of the phosphorylated peptide $\left(\mathrm{r}=\frac{\text { Area(biot-Add) }}{\text { Area(biot-pAdd })}=4.4\right)$. After BEM in the optimized conditions (Figure 5b), the signal of the $\left\{-\mathrm{H}_{3} \mathrm{PO}_{4}\right\}$ biot-pAdd peptide $(\mathrm{m} / \mathrm{z} 1661.8)$ was observed, with a three-fold increase in ionization efficiency with regards to biot-pAdd $\left(\mathrm{r}^{\prime}=\frac{\text { Area }(\text { biot-Add })}{\text { Area }\left\{\left\{-\mathrm{H}_{3} \mathrm{PO}_{4}\right\} \text { biot-pAdd }\right)}=1.5\right)$. The BEM was not total as shown by the persistence of a low intense signal at $m / z 1759.8$. Few secondary reactions were observed.

The drastic ionization gain is also exemplified by the detection limits available for these peptides in MALDI-TOF MS. In a direct analysis, the detection limit for the non phosphorylated peptide biot-Add was $100 \mathrm{fmol}$ on target while it was $1 \mathrm{pmol}$ on target for the phosphorylated peptide biotpAdd. After BEM, the detection limit for $\left\{-\mathrm{H}_{3} \mathrm{PO}_{4}\right\}$ biot-pAdd was of $100 \mathrm{fmol}$. It is thus possible to reach similar detection limits than with the nonphosphorylated peptide.

This study on $\beta$-elimination was performed on a phosphorylated peptide with a cysteine residue and on its nonphosphorylated counterpart. This phosphopeptide is very poorly enriched by methods such as IMAC or MOC [25], and separating it from its non phosphorylated counterpart before MS analysis is therefore difficult. Specific tools addressed to this class of highly basic phosphopeptides are still lacking. It was shown that the cysteine residue in this sequence was particularly reactive towards $\beta$-elimination. Although this was not surprising, the fact that the protection of the cysteine residue by alkylation with iodoacetamide led only to minor improvement is more puzzling and should be taken into account when working on a sample without previous knowledge. It would be particularly problematic if the BEM is coupled with a Michael addition intended to tag the phosphopeptides for selective enrichment, since cysteine residues would present a high risk to be enriched as well. Elimination of $\mathrm{H}_{2} \mathrm{O}$ on the nonphosphorylated serine residue was also observed, giving a product similar to the $\left\{-\mathrm{H}_{3} \mathrm{PO}_{4}\right\}$ biot-pAdd peptide. This would be overlooked if only mixture of peptides were studied, without having access to the two forms separately. Even though this side reaction was minor, it can prevent the ability to distinguish between elimination involving the serine and the phosphoserine residues. However, most of the biologically relevant studies would imply such a mixture.

Optimizations of the experimental conditions were made that allowed a drastic decrease of these side reactions. The most striking improvement was obtained by performing the BEM reaction in $30 \% A C N$ instead of $\mathrm{H}_{2} \mathrm{O}$. These conditions were already reported in the literature, but were mostly said to increase the rate of the reaction [31, 32], and the interest of adding organic solvent is debated [34, 35]. It was once mentioned that ACN protected the peptides [29]. In this study, working in $30 \% \mathrm{ACN}$ did not speed up the reaction (Figure 3a), but dramatically increased the selectivity of the BEM towards the phosphate group (Figures $3 \mathrm{~b}$ and 4). To explain the low abundance of the side reactions in $30 \% \mathrm{ACN}$, a polar aprotic solvent, one might argue that in polar protic solvent such as water, hydrogen bonds will stabilize the hydroxyl group of the serine residue, enhancing its leaving ability. $-\mathrm{OH}$ is not a good leaving group and will be even less stabilized in ACN than in $\mathrm{H}_{2} \mathrm{O}$, which might explain the decrease in reactivity of the serine residue. The same stands for the -SH group of the cysteine residue, to a lesser extent. Moreover, the difference of reactivity in these solvents might be explained by differences in peptide structure. We have previously reported an NMR study in $2 \%$ TFA of the peptides biot-Add and biot-pAdd. This study indicated that the presence of the proline residue favored a turn structure and that the phosphate group probably forms a salt bridge with the guanidinium group of the arginine residue.

In addition to a solvent containing $30 \%$ of $\mathrm{ACN}$, optimizations regarding the reaction temperature and time were performed. For these peptide sequences, working at room temperature for $4 \mathrm{~h}$ was preferred. In these conditions, the production of $\left\{-\mathrm{H}_{3} \mathrm{PO}_{4}\right\}$ biot-pAdd was the major reaction observed on biot-pAdd, and few side reactions occurred on the non phosphorylated biot-Add peptide. The removal of the phosphate group was not easy on this sequence, as shown by the rather long reaction time required. This is probably caused by the turn structure [25] and by the proximity of the proline residue from the phosphoserine residue [51]. It should be again emphasized that the reproducibility of the reaction in the experimental conditions tested was globally low, which should be considered as another reason to be cautious.

\section{Conclusions}

The $\beta$-elimination is an attractive method in order to improve the MS detection of phosphorylated peptides. Through a simple chemical reaction, it allows the removal of the phosphate group and a strong enhancement in ionization efficiencies. However, the lack of sensitivity of the methods makes it dangerous to use in routine phosphoproteomics analysis. Optimizations were made that enhanced the selectivity of the $\beta$-elimination towards the phosphate group with no negative impact on the reaction performance. However, we want to emphasize three conclusions. First, protection of the cysteine residue by alkylation is not sufficient to fully prevent unwanted BEM on this residue. Second, these optimizations on the $\beta$-elimination reaction could be extremely dependent on the peptide sequences. Knowing this, it seems difficult to use the BEM strategy on 
an unknown sample. Third, even with the drastic improvement observed here, the selectivity of the reaction does not seem sufficient to work on a mixture between the phosphorylated and nonphosphorylated forms of this sequence. A previous fractionation of the samples seems to us necessary. When these precautions were taken, the ionization improvement offered by the BEM of the phosphate group was strong (a 3-fold enhancement in the case presented here).

\section{References}

1. Cohen, P.: The regulation of protein function by multisite phosphorylation - a 25 year update. Trends Biochem. Sci. 25(12), 596-601 (2000)

2. Manning, G., Whyte, D.B., Martinez, R., Hunter, T., Sudarsanam, S.: The protein kinase complement of the human genome. Science 298 (5600), 1912-1934 (2002)

3. Hubbard, M.J., Cohen, P.: On target with a new mechanism for the regulation of protein phosphorylation. Trends Biochem. Sci. 18(5), 172177 (1993)

4. Trost, M., Bridon, G., Desjardins, M., Thibault, P.: Subcellular phosphoproteomics. Mass Spectrom. Rev. 29(6), 962-990 (2010)

5. Anbalagan, M., Huderson, B., Murphy, L., Rowan, B.G.: Posttranslational modifications of nuclear receptors and human disease. Nucl. Recept. Signal. 10, e001 (2012)

6. Lisman, J., Yasuda, R., Raghavachari, S.: Mechanisms of CaMKII action in long-term potentiation. Nat. Rev. Neurosci. 13(3), 169-182 (2012)

7. Sun, H., Wang, Y.: Novel Ser/Thr protein phosphatases in cell death regulation. Physiology (Bethesda) 27(1), 43-52 (2012)

8. Scott, J.D., Pawson, T.: Cell signaling in space and time: Where proteins come together and when they're apart. Science 326(5957), 1220-1224 (2009)

9. Cohen, P.: The origins of protein phosphorylation. Nat. Cell Biol. 4(5), E127-E130 (2002)

10. Rainer, M., Sonderegger, H., Bakry, R., Huck, C.W., Morandell, S., Huber, L.A., Gjerde, D.T., Bonn, G.K.: Analysis of protein phosphorylation by monolithic extraction columns based on poly(divinylbenzene) containing embedded titanium dioxide and zirconium dioxide nano-powders. Proteomics 8, 4593-4602 (2008)

11. DeGnore, J.P., Qin, J.: Fragmentation of phosphopeptides in an ion trap mass spectrometer. J. Am. Soc. Mass Spectrom. 9(11), 1175-1188 (1998)

12. Palumbo, A.M., Tepe, J.J., Reid, G.E.: Mechanistic insights into the multistage gas-phase fragmentation behavior of phosphoserine- and phosphothreonine-containing peptides. J. Proteome Res. 7(2), 771-779 (2008)

13. Tholey, A., Reed, J., Lehmann, W.D.: Electrospray tandem mass spectrometric studies of phosphopeptides and phosphopeptide analogues. J. Mass Spectrom. 34(2), 117-123 (1999)

14. Kratzer, R., Eckerskorn, C., Karas, M., Lottspeich, F.: Suppression effects in enzymatic peptide ladder sequencing using ultraviolet-matrix assisted laser desorption/ionization-mass spectormetry. Electrophoresis 19(11), 1910-1919 (1998)

15. McLachlin, D.T., Chait, B.T.: Analysis of phosphorylated proteins and peptides by mass spectrometry. Curr. Opin. Chem. Biol. 5(5), 591-602 (2001)

16. Porath, J., Carlsson, J., Olsson, I., Belfrage, G.: Metal chelate affinity chromatography, a new approach to protein fractionation. Nature $\mathbf{2 5 8}$ (5536), 598-599 (1975)

17. Posewitz, M.C., Tempst, P.: Immobilized Gallium(III) Affinity Chromatography of Phosphopeptides. Anal. Chem. 71, 2883-2892 (1999)

18. Ueda, E.K.M., Gout, P.W., Morganti, L.: Current and prospective applications of metal ion-protein binding. J. Chromatogr. A 988, 1-23 (2003)

19. McGill, P.R., Idriss, H.: Ab Initio Study of Surface Acid-base Reactions. The Case of Molecular and Dissociative Adsorption of Ammonia on the (011) Surface of Rutile TiO. Langmuir 24(1), 97-104 (2008)

20. Nawrocki, J., Dunlap, C., McCormick, A., Carr, P.W.: Part I. Chromatography using ultra-stable metal oxide-based stationary phases for HPLC. J. Chromatogr. A 1028, 1-30 (2004)
21. Pinkse, M.W., Uitto, P.M., Hilhorst, M.J., Ooms, B., Heck, A.J.: Selective isolation at the femtomole level of phosphopeptides from proteolytic digests using 2D-NanoLC-ESI-MS/MS and titanium oxide precolumns. Anal. Chem. 76(14), 3935-3943 (2004)

22. Larsen, M.R., Thingholm, T.E., Jensen, O.N., Roepstorff, P., Jorgensen, T.J.: Highly selective enrichment of phosphorylated peptides from peptide mixtures using titanium dioxide microcolumns. Mol. Cell Proteomics 4(7), 873-886 (2005)

23. Tsai, C.F., Wang, Y.T., Chen, H.R., Lai, C.Y., Lin, P.Y., Pan, K.T., Chen, J.Y., Khoo, K.H., Chen, Y.J.: Imobilized Metal Affinity Chromatography Revisited: $\mathrm{pH} /$ Acid Control towards High Selectivity in Phosphoproteomics. J. Proteome Res. 7(9), 4058-4069 (2008)

24. Klemm, C., Otto, S., Wolf, C., Haseloff, R.F., Beyermann, M., Krause, E.: Evaluation of the titanium dioxide approach for MS analysis of phosphopeptides. J. Mass Spectrom. 41(12), 1623-1632 (2006)

25. Matheron, L., Sachon, E., Burlina, F., Sagan, S., Lequin, O., Bolbach, G.: Sequence-dependent enrichment of a model phosphopeptide: A combined MALDI-TOF and NMR study. Anal. Chem. 83(8), 3003-3010 (2011)

26. Wilson-Grady, J.T., Villen, J., Gygi, S.P.: Phosphoproteome analysis of fission yeast. J. Proteome Res. 7(3), 1088-1097 (2008)

27. Zhou, H., Low, T.Y., Hennrich, M.L., van den Toorn, H., Schwend, T., Zou, H., Mohammed, S., Heck, A.J.: Enhancing the identification of phosphopeptides from putative basophilic kinase substrates using $\mathrm{Ti}$ (IV) based IMAC enrichment. Mol. Cell Proteomics 10(10), M110.006452 (2011)

28. Simpson, D.L., Hranisavljevic, J., Davidson, E.A.: Elimination and sulfite addition as a means of localization and identification of substituted seryl and threonyl residues in proteins and proteoglycans. Biochemistry 11(10), 1849-1856 (1972)

29. Meyer, H.E., Hoffmann-Posorske, E., Korte, H., Heilmeyer Jr., L.M.: Sequence analysis of phosphoserine-containing peptides. Modification for picomolar sensitivity. FEBS Lett. 204(1), 61-66 (1986)

30. Byford, M.F.: Rapid and selective modification of phosphoserine residues catalysed by $\mathrm{Ba} 2+$ ions for their detection during peptide microsequencing. Biochem. J. 280(Pt 1), 261-265 (1991)

31. Mattila, K., Siltainsuu, J., Balaspiri, L., Ora, M., Lonnberg, H.: Derivatization of phosphopeptides with mercapto- and amino-functionalized conjugate groups by phosphate elimination and subsequent Michael addition. Org. Biomol. Chem. 3(16), 3039-3044 (2005)

32. Klemm, C., Schroder, S., Gluckmann, M., Beyermann, M., Krause, E.: Derivatization of phosphorylated peptides with $\mathrm{S}$ - and $\mathrm{N}$-nucleophiles for enhanced ionization efficiency in matrix-assisted laser desorption/ ionization mass spectrometry. Rapid Commun. Mass Spectrom. 18(22), 2697-2705 (2004)

33. Knight, Z.A., Schilling, B., Row, R.H., Kenski, D.M., Gibson, B.W., Shokat, K.M.: Phosphospecific proteolysis for mapping sites of protein phosphorylation. Nat. Biotechnol. 21(9), 1047-1054 (2003)

34. van der Veken, P., Dirksen, E.H., Ruijter, E., Elgersma, R.C., Heck, A.J., Rijkers, D.T., Slijper, M., Liskamp, R.M.: Development of a novel chemical probe for the selective enrichment of phosphorylated serine- and threonine-containing peptides. Chembiochem 6(12), 2271-2280 (2005)

35. Reinders, J., Meyer, H.E., Sickmann, A.: Applications of highly sensitive phosphopeptide derivatization methods without the need for organic solvents. Proteomics 6(9), 2647-2649 (2006)

36. Thompson, A.J., Hart, S.R., Franz, C., Barnouin, K., Ridley, A., Cramer, R.: Characterization of protein phosphorylation by mass spectrometry using immobilized metal ion affinity chromatography with on-resin $\beta$ elimination and Michael addition. Anal. Chem. 75(13), 3232-3243 (2003)

37. Li, H., Sundararajan, N.: Charge switch derivatization of phosphopeptides for enhanced surface-enhanced Raman spectroscopy and mass spectrometry detection. J. Proteome Res. 6(8), 2973-2977 (2007)

38. Kwon, S.J., Choi, E.Y., Seo, J.B., Park, O.K.: Isolation of the Arabidopsis phosphoproteome using a biotin-tagging approach. Mol. Cell 24(2), 268-275 (2007)

39. Molloy, M.P., Andrews, P.C.: Phosphopeptide derivatization signatures to identify serine and threonine phosphorylated peptides by mass spectrometry. Anal. Chem. 73(22), 5387-5394 (2001)

40. Oda, Y., Nagasu, T., Chait, B.T.: Enrichment analysis of phosphorylated proteins as a tool for probing the phosphoproteome. Nat. Biotechnol. 19(4), 379-382 (2001)

41. Jalili, P.R., Sharma, D., Ball, H.L.: Enhancement of ionization efficiency and selective enrichment of phosphorylated peptides from complex protein mixtures using a reversible poly-histidine tag. J. Am. Soc. Mass Spectrom. 18(6), 1007-1017 (2007) 
42. McLachlin, D.T., Chait, B.T.: Improved $\beta$-elimination-based affinity purification strategy for enrichment of phosphopeptides. Anal. Chem. 75(24), 6826-6836 (2003)

43. Stevens Jr., S.M., Chung, A.Y., Chow, M.C., McClung, S.H., Strachan, C.N., Hamon, A.C., Denslow, N.D., Prokai, L.: Enhancement of phosphoprotein analysis using a fluorescent affinity tag and mass spectrometry. Rapid Commun. Mass Spectrom. 19, 2157-2162 (2005)

44. Ahn, Y.H., Ji, E.S., Lee, J.Y., Cho, K., Yoo, J.S.: Arginine-mimic labeling with guanidinoethanethiol to increase mass sensitivity of lysine-terminated phosphopeptides by matrix-assisted laser desorption/ ionization time-of-flight mass spectrometry. Rapid Commun. Mass Spectrom. 21(14), 2204-2210 (2007)

45. Ahn, Y.H., Ji, E.S., Lee, J.Y., Cho, K., Yoo, J.S.: Coupling of TiO(2)mediated enrichment and on-bead guanidinoethanethiol labeling for effective phosphopeptide analysis by matrix-assisted laser desorption/ ionization mass spectrometry. Rapid Commun. Mass Spectrom. 21(24), 3987-3994 (2007)

46. Steen, H., Mann, M.: A new derivatization strategy for the analysis of phosphopeptides by precursor ion scanning in positive ion mode. J. Am. Soc. Mass Spectrom. 13(8), 996-1003 (2002)

47. Chen, M., Su, X., Yang, J., Jenkins, C.M., Cedars, A.M., Gross, R.W.: Facile identification and quantitation of protein phosphorylation via $\beta$-elimination and Michael addition with natural abundance and stable isotope labeled thiocholine. Anal. Chem. 82(1), 163-171 (2010)

48. Baumgart, S., Lindner, Y., Kuhne, R., Oberemm, A., Wenschuh, H., Krause, E.: The contributions of specific amino acid side chains to signal intensities of peptides in matrix-assisted laser desorption/ ionization mass spectrometry. Rapid Commun. Mass Spectrom. 18(8), 863-868 (2004)

49. Nielsen, M.L., Savitski, M.M., Kjeldsen, F., Zubarev, R.A.: Physicochemical properties determining the detection probability of tryptic peptides in Fourier transform mass spectrometry. A correlation study. Anal. Chem. 76(19), 5872-5877 (2004)

50. Valero, M.-L., Giralt, E., Andreu, D.: An investigation of residuespecific contributions to peptide desorption in MALDI-TOF mass spectrometry. Lett. Pept. Sci. 6(2/3), 109-115 (1999)

51. Arrigoni, G., Resjo, S., Levander, F., Nilsson, R., Degerman, E., Quadroni, M., Pinna, L.A., James, P.: Chemical derivatization of phosphoserine and phosphothreonine containing peptides to increase sensitivity for MALDI-based analysis and for selectivity of MS/MS analysis. Proteomics 6(3), 757-766 (2006)

52. Tsumoto, H., Ra, M., Samejima, K., Taguchi, R., Kohda, K.: Chemical derivatization of peptides containing phosphorylated serine/threonine for efficient ionization and quantification in matrix-assisted laser desorption/ionization time-of-flight mass spectrometry. Rapid Commun. Mass Spectrom. 22(7), 965-972 (2008)

53. Goshe, M.B., Conrads, T.P., Panisko, E.A., Angell, N.H., Veenstra, T.D., Smith, R.D.: Phosphoprotein isotope-coded affinity tag approach for isolating and quantitating phosphopeptides in proteome-wide analyses. Anal. Chem. 73(11), 2578-2586 (2001)

54. Li, W., Backlund, P.S., Boykins, R.A., Wang, G., Chen, H.C.: Susceptibility of the hydroxyl groups in serine and threonine to $\beta$ elimination/Michael addition under commonly used moderately hightemperature conditions. Anal. Biochem. 323(1), 94-102 (2003)

55. Sachon, E., Clodic, G., Blasco, T., Jacquot, Y., Bolbach, G.: In-source fragmentation of very labile peptides in matrix-assisted laser desorption/ ionization time-of-flight mass spectrometry. Anal. Chem. 81(21), 89868992 (2009)

56. Gobom, J., Nordhoff, E., Mirgorodskaya, E., Ekman, R., Roepstorff, P.: Sample purification and preparation technique based on nano-scale reversed-phase columns for the sensitive analysis of complex peptide mixtures by matrix-assisted laser desorption/ionization mass spectrometry. J. Mass Spectrom. 34(2), 105-116 (1999) 